\title{
Genetic Analysis of the pX Region in Bovine Leukemia Virus genotype 1 in Holstein Friesian Cattle with Different Stages of Infection
}

\section{Neli Montero Machuca}

UNAM FESC: Universidad Nacional Autonoma de Mexico Facultad de Estudios Superiores Cuautitlan Jorge Luis Tórtora Pérez

UNAM FESC: Universidad Nacional Autonoma de Mexico Facultad de Estudios Superiores Cuautitlan

\section{Ana Silvia González Méndez}

UNAM FESC: Universidad Nacional Autonoma de Mexico Facultad de Estudios Superiores Cuautitlan

\section{Lucia Angelica García-Camacho}

UNAM FESC: Universidad Nacional Autonoma de Mexico Facultad de Estudios Superiores Cuautitlan

\section{Ernesto Marín Flamand}

UNAM FESC: Universidad Nacional Autonoma de Mexico Facultad de Estudios Superiores Cuautitlan

Hugo Ramírez Álvarez ( $\nabla$ ramiralh@unam.mx )

Universidad Nacional Autonoma de Mexico Facultad de Estudios Superiores Cuautitlan

https://orcid.org/0000-0003-1682-8104

\section{Research Article}

Keywords: Enzootic bovine leucosis, pX region, lymphoma, PCR, phylogeny

Posted Date: June 7th, 2021

DOl: https://doi.org/10.21203/rs.3.rs-570327/v1

License: (c) (i) This work is licensed under a Creative Commons Attribution 4.0 International License.

Read Full License 


\section{Abstract}

The pX genetic region of the Bovine Leukemia Virus (BLV) includes four genes with overlapping reading frames that code for the Tax, Rex, R3 and G4 proteins. These proteins are involved in the regulation of transcriptional and post-transcriptional viral expression, as well as having oncogenic potential. Our goal was to determine the pathogenic role associated with BLV genotype $1 \mathrm{pX}$ region genetics in terms of lymphocytosis, lymphomas and proviral load.

We screened 724 serological samples from mixed-age Holstein Friesian cattle from six states in Mexico. Once peripheral blood leukocytes were isolated from whole blood with anticoagulant, we extracted genomic DNA using a commercial kit. Then, we designed in silico primers that hybridize in conserved regions of the BLV pX region, which allowed for PCR standardization to detect proviral DNA in infected cells. Positive amplicons were sequenced using the Sanger method, obtaining 1156 nucleotide-long final sequences that included the four $\mathrm{pX}$ region genes. The 30 heads of cattle that formed the genetic study population included 12 with lymphocytosis, 12 without lymphocytosis and six with lymphoma.

Lymphoma presence was determined in six bovine tumor tissues using histopathology, and we identified BLV presence with in situ hybridization.

Phylogenetic analysis determined that the 30 sequences were associated with genotype 1, and genetic distance between the sequences ranged from $0.2 \%-2.09 \%$. We identified two sequences in the G4 gene, one with a three-nucleotide deletion (AGU_7488L, in a cow with lymphocytosis), and one with a nine nucleotide deletion (AGU_18A, in a cow without lymphocytosis). PX region analysis identified positive selection in the G4, rex and R3 genes, and we found no difference in proviral load between the studied groups. It was not possible to establish an association between $\mathrm{pX}$ region variability and the development of lymphocytosis, lymphoma, asymptomatic status and proviral load in BLV-infected cattle.

\section{Introduction}

Enzootic Bovine Leukosis (EBL) is the disease most associated with neoplasm development in cattle, and mainly affects dairy cattle $[1,2]$. EBL reduces milk production, causes carcasses to be seized at the slaughterhouse due to the presence of lymphosarcomas [3], and decreases the productive longevity of animals, as well as hindering their export [4, 5]. Most infected cattle are asymptomatic, about a third may develop persistent lymphocytosis (LP) characterized by polyclonal B cell expansion, and an additional $5 \%$ to $10 \%$ of cattle may develop lymphoma or fatal B cell lymphosarcoma after a long latency period in adult animals [6-8]

Bovine leukemia virus (BLV) is the causal agent of EBL. It belongs to the order Ortervirales, family Retroviridae and genus Deltaretrovirus $[9,10]$. BLV is B-lymphotropic and oncogenic, and related both structurally and biologically to human T-lymphotropic viruses HTLV-I and HTLV-II [11]. All retroviruses comprise essential, gag, pro, pol and env genes, which are necessary for infectious virus production. These are flanked by two identical long terminal repeat sequences (LTRs; [12]). Unlike simple retroviruses, 
the Deltaretrovirus genome is made up of accessory genes with overlapping reading frames that code for various regulatory and accessory proteins (Tax, Rex, R3, and G4) in the pX region [13].

Tax and Rex proteins are important in nuclear export of viral RNA to the cytoplasm, for viral transcription regulation, and in the transformation of BLV-induced leukemogenesis [14]. Tax proteins also interact with Ha-ras oncogenes inducing in vitro immortalization and transformation of rat embryo fibroblasts. These transformed cells cause tumors in nude mice $[15,16]$. Accessory proteins R3 and G4 contribute to high viral load maintenance and, additionally, G4 proteins exhibit transforming potential in primary rat embryo fibroblasts when co-expressed with the Ha-ras oncogene [17].

During the chronic infection stage, deltaretroviruses promote infected cell proliferation through transient accessory protein (Tax) action, and propagate during the mitotic division of infected cells. In primary tumor cells, only highly sensitive methods, such as reverse transcription PCR (RT-PCR), and in situ hybridization can detect the limited quantities of deltaretroviral RNA. EBL development requires Tax expression, at least during early infection stages. Viral expression activation in latently infected cells and escape from cytotoxic lymphocyte (CTLs) response are essential steps in pathogenesis [18].

BLV genotypes 1 and 3 have been identified in dairy cattle in Mexico using phylogenetic analyses based on the env gene $[19,20]$. However, there are no studies on the $\mathrm{pX}$ region and its role in pathogenesis. The aim of our study was to genetically analyze the pX region of BLV genotype 1 , and its possible association with proviral load, lymphocytosis or development of lymphomas in Holstein Friesian cattle.

\section{Materials And Methods}

\section{Animals and samples}

The study population was made up of 724 Holstein Friesian cows that were between two and three years old. We used non-probabilistic sampling for convenience with cooperating ranchers, from dairy herds in six states across Mexico (Aguascalientes, Coahuila, Guanajuato, Hidalgo, Puebla and Tlaxcala). Wholeblood samples were obtained by coccygeal venipuncture from each animal in tubes with sodium heparin (BD Vacutainer ${ }^{\circledR}$, USA). Over a six-month period, we collected tumors from different organs in animals destined for slaughter in the state of Hidalgo. These tumors were preserved in $10 \%$ buffered formalin while other tissues were frozen at $-75^{\circ} \mathrm{C}$. Formalin-fixed samples were embedded in paraffin and $4 \mu \mathrm{m}$ histological sections were made for subsequent staining with hematoxylin-eosin. Other samples were intended for in situ hybridization. The study was endorsed by the Internal Committee on Animal Use, and Experimentation of the Graduate Program in Animal Production and Health Sciences at the National Autonomous University of Mexico, under code MC-2017 / 1-7-UNAM.

\section{White blood cell count, peripheral blood leukocyte and plasma collection}

We used $1 \mathrm{ml}$ of blood with heparin (Vacutainer ${ }^{\circledR}$ BD U.S.A) to carry out leukocyte counts in a Neubauer chamber, as well as differential counts by means of smears stained with diff quick (Hycel de México®, 
Mexico). The rest of the blood sample $(7 \mathrm{ml})$ was centrifuged at $350 \otimes \mathrm{g}$ for 15 minutes to separate plasma, which was collected in $1.5 \mathrm{~mL}$ microtubes. Peripheral blood leukocytes (PBLs) were then processed with lysis solutions [21]. Plasma samples and PBLs were stored at $-70^{\circ} \mathrm{C}$ until use.

\section{In situ hybridization (ISH)}

We placed $4 \mu \mathrm{m}$ tissue sections on electrocharged slides (Probe On Plus, Fisher Scientific, Pittsburg, USA), heated them on a thermal stage at $60^{\circ} \mathrm{C}$ for 30 minutes, and then de-paraffinized them in three 5 -minute xylene passes. The tissue samples were then rehydrated in ethanol gradients (two 5-minute passes in $100 \%$ ethanol, one 2 -minute pass in $95 \%$ ethanol, and one 2-minute pass in $70 \%$ ethanol), followed by one 1-minute pass in $1 \mathrm{X}$ automation buffer (Automation buffer, Biomeda Corp., Foster City CA, USA).

ISH reactions were performed in a Microprobe Manual Staining System workstation (Fisher Scientific, Pittsburg, USA) following a standard protocol that consisted of the following steps: predigestion and digestion with $0.25 \%$ pepsin (Fisher, Scientific, Pittsburg, USA) in a $2.0 \mathrm{pH}$ automation buffer. Prehybridization with 100\% formamide (Promega Corp. Madison, WI, USA), hybridization with $2.5 \mathrm{ng} / \mu \mathrm{l}$ of the specific BLV DNA probe in hybridization solution (chondroitin sulfate 7.5\%, 5X Citrates / SSC saline solution, $50 \mathrm{nM}$ Phosphate Buffer, $0.25 \%$ Blocking Agent, 22.5\% Formamide). Followed by high stringency washes with $0.5 \%$ and $0.2 \%$ SSC (Promega Corp. Madison, WI, USA), blocking with Buffer $1(\mathrm{NaCl} 0.15 \mathrm{M}$, $0.1 \mathrm{M}$ Tris $\mathrm{HCl}, \mathrm{pH} 7.5$ ) supplemented with $0.3 \%$ Triton X-100 (Fisher Scientific, Pittsburg, USA) and $1 \%$ sheep serum.

Detection was performed with a 1:500 dilution of anti-digoxigenin conjugated with alkaline phosphatase (Roche Applied Sciences, Mannheim, Germany) and developed with $0.45 \%$ blue-nitro-tetrazolium (NBT) and 5-bromocresyl-3-indolylphosphate (BCIP) at 0.35\% (Roche Applied Sciences, Mannheim, Germany) in Buffer $2\left(\mathrm{MgCl}_{2} 0.06 \mathrm{M}, \mathrm{NaCl} 0.12 \mathrm{M}\right.$, Tris $0.1 \mathrm{M} \mathrm{pH}$ 9.5) supplemented with Tween 20 at $0.4 \%$ (Hycel de México SA de CV) and Brij 35 0.25\% (Fisher Scientific, Pittsburg, USA). The reaction was stopped with distilled water and fast green (Hycel de México S.A. de C.V.) was applied as a contrast dye and permanent mounting medium (Entellan, Merck, Hamburg, Germany). Each ISH protocol had a positive and a negative control. Likewise, each problem lamella was processed in the absence of the labeled probe as an internal hybridization control.

The probe was obtained by direct labeling with digoxigenin, using a set of commercial reagents (PCR DIG Probe synthesis Kit, Roche Biochemical, Diagnostic, Mannheim, Germany). We used the 202 bp product of the BLV polgene as a template for labeling.

\section{Serological analysis}

To determine the presence of antibodies against BLV, we evaluated plasma with an indirect enzymelinked immunosorbent assay (ELISA) that identifies antibodies against the gp51 protein of the virus, following the manufacturer's instructions (VMRD Inc., Pullman, WA. USA). 


\section{DNA extraction}

We performed DNA extraction from PBLs using a commercial kit (FavorPrepTM TissueGenomic DNA Extraction Mini Kit Favorgen, Taiwan), following the manufacturer's instructions. DNA was quantified at 260-280 nm absorbance in a nanodrop (Thermo fisher Scientific, USA) and stored at $-70^{\circ} \mathrm{C}$ until use.

\section{Primers}

Nucleotide sequences used for primer design were some of the available GenBank sequences of BLV genotypes 1-4, 6, 9 and 10. We used BioEdit and Primer3 input V4.0 programs to design three sets of overlapping primers to amplify the entire $\mathrm{pX}$ region (Table 1 ).

\section{BLV pX region PCRs}

To amplify the $\mathrm{pX}$ region from BLV proviral DNA, we standardized three PCRs based on the amplification of positive controls, which were obtained from a PCR-positive field sample and confirmed by sequencing and inserted into a plasmid following manufacturer's instructions for the commercial Thermo Scientific InsTAclone PCR Cloning kit (Thermo Fisher Scientific ${ }^{\text {TM }}$ USA).

The PCR reaction mixture was: $1 \mathrm{X}$ buffer (Amplificasa ${ }^{\circledR}$ Biotecmol, Mexico), $1.5 \mathrm{mM} \mathrm{MgCl} 2$ (Amplificasa ${ }^{\circledR}$ Biotecmol, Mexico), $230 \mu \mathrm{M}$ dNTPs (Kappa Biosystems, USA), $400 \mathrm{nM}$ of each primer, $5 \mathrm{U}$ of Taq DNA Polymerase (Amplificasa ${ }^{\circledR}$ Biotecmol, Mexico), and $500 \mathrm{ng}$ of DNA for a final $30 \mu \mathrm{L}$ volume.

PCR amplification conditions were carried out in a thermal cycler (BIOER, China), and consisted of one initial denaturation cycle at $95^{\circ} \mathrm{C}$ for $5 \mathrm{~min}$, followed by 30 denaturation cycles at $95^{\circ} \mathrm{C}$ for $30 \mathrm{~s}$, hybridization at $54^{\circ} \mathrm{C}(\mathrm{PCR}-1) / 56^{\circ} \mathrm{C}$ (PCR-2) / $47^{\circ} \mathrm{C}$ (PCR-3) for $40 \mathrm{~s}$ and extension at $72^{\circ} \mathrm{C}$ for $50 \mathrm{~s}$, with a final extension cycle at $72^{\circ} \mathrm{C}$ for $15 \mathrm{~min}$. To visualize PCR products, these were separated via electrophoresis in $1.5 \%$ agarose gels, stained with EtBr ethidium bromide $(5 \mu \mathrm{g} / \mu \mathrm{l})$. A base pair marker (Cleaver Scientific, UK) was used as a reference, applying electrical current at 110 volts for one hour for later visualization under UV light in a transilluminator (UVP®, USA).

\section{Sequencing}

We purified positive samples using a commercial FavorPrep GEL/PCR Purification Kit (Favorgen, Taiwan) following the manufacturer's instructions. The purified PCR product was sequenced using the Sanger method with the ABI 3130x1 Genetic analyzer (Applied Biosystems, Foster City, CA, USA). Sequencing was carried out in both directions with the specific primers for each product.

\section{Sequence analysis and phylogeny}

We used ClustalW for sequence alignment, and the similarity matrices were determined with BioEdit v7.0.4. Amino acid deduction and genetic distance measurements were performed with Geneious v11.0.3

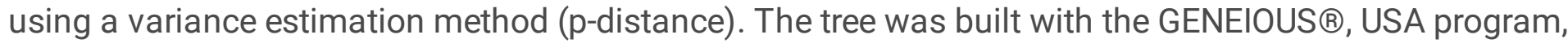


using the MrBayes algorithm which is based on the Markov Monte Carlo (MCMC) model [22]. FigTree ${ }^{\circledR}$ v1.4.3. was used to edit the tree. We determined the synonymous and non-synonymous substitution rate using SNAP (Synonymous Non-synonymous Analysis Program) v2.1.1 [23]; https://www.hiv.lanl.gov/content/sequence/SNAP/SNAP.html.

\section{Proviral load}

We determined proviral load using qPCR in $20 \mu$ reactions in a commercial Sensi Fast SYBR Lo-Rox Master Mix kit (Bioline, London, UK). We used 50 ng of cDNA, with the Strategene Mx3005P detection and amplification system (Agilent Technologies, USA). Each sample was evaluated in duplicate and with a non-tempered control reaction (NTC / Non Template Control) in 96-well optical plates (Agilent Technologies, USA). We used the following conditions: $95^{\circ} \mathrm{C}$ for $2 \mathrm{~min}$, followed by denaturation $5 \mathrm{sec}$. at $95^{\circ} \mathrm{C}$, alignment $10 \mathrm{sec}$. at $60^{\circ} \mathrm{C}$, elongation $10 \mathrm{sec}$. at $72^{\circ} \mathrm{C}$, for 45 cycles. Following amplification, we increased the temperature to $95^{\circ} \mathrm{C}$ to construct a dissociation curve and determined the specificity of the amplified product.

\section{Quantification method}

We used a relative quantification method, comparing the cross-point/CP. Constitutive gene hypoxanthineguanine phosphoribosyltransferase (HPRT) was used as the internal control, and the procedure reported by Livak and Schmittgen [24] was used as the calculation method.

\section{Results}

\section{BLV infection detection}

The presence of antibodies against BLV was demonstrated in 405 animals (55.9\%), which were then classified as cattle without lymphocytosis if their leucocyte counts fell below 7,500 leukocytes $/ \mathrm{mm}^{3}$, and as cattle with lymphocytosis when their leucocyte counts were above 10,000 leukocytes $/ \mathrm{mm}^{3}$ [25]. Differential counts confirmed lymphocytosis in the second group (Table 2).

\section{Histopathology and in situ hybridization}

At necropsy, nine cows presented tumoral lesions in the abomasum, heart, lymph nodes and kidneys. These tissues were analyzed by means of histopathology, and all cases showed cellular alterations suggestive of BLV infection (Figure $1 \mathrm{~A}, \mathrm{~B}, \mathrm{D}$ and $\mathrm{E}$ ). Lymphomas only presented positive ISH signals in six cases (Figure $1 \mathrm{C}$ and $\mathrm{F}$ ).

\section{Determination of proviral load}

To determine the association between proviral load and the different test groups (with lymphocytosis, without lymphocytosis and with lymphoma), we tested the proviral load of the 30 sequenced samples. 
Then we ran ANOVAs and Tukey tests $(p<0.05)$ on the results between the groups, and used the $\log 10^{2-} \triangle \triangle C p$ value as a dependent variable, using the Statgraphics Centurion 18 statistical package.

Cattle groups with and without lymphocytosis showed proviral load values of 3.325 and 3.265 respectively, and both of these were higher than values from the group with lymphoma (2.655), however the values between groups were not statistically different $(p>0.05)$.

\section{PCR amplification of the $\mathrm{pX}$ region of BLV}

We carried out PCRs on seropositive samples to amplify the complete BLV pX region and sequenced two samples per region and six lymphomas. We obtained a total of 30 samples from 12 cattle without lymphocytosis, 12 with lymphocytosis and six with lymphoma.

\section{Phylogeny}

We constructed a phylogenetic tree (Figure 2) to determine the prevalent BLV genotype in our samples $(n=30)$. The tree included reference sequences from the $p X$ region of BLV genotypes 1-4, 6, 9 and 10, that are available in GenBank. The sequences we obtained in this study were deposited in GenBank and are available under accession numbers MN707591 to MN707620. All of our samples, independently of which study group they belonged to (without lymphocytosis, with lymphocytosis and lymphoma), or geographical provenance, were associated with genotype 1 . Samples were distributed heterogeneously throughout the clade and there was no association by infection phase nor geographic region (Figure 2).

\section{Sequence analysis}

Genetic variability found between the BLV nucleotide sequences we obtained in the study showed genetic distances ranging from 0.2 to 2.09 (Table 3 ). We determined there was negative selection in the proportion of synonymous to non-synonymous mutations in most of the genes and study groups. We also found positive selection in the $G 4$ gene for cattle in all the three study groups, in the rex gene in cattle with lymphoma, and in the $R 3$ gene in cattle with lymphocytosis (Table 3 ). We found different changes among $R 3, G 4$, rex and tax gene derived residue alignment from the 30 sequences, as well as deletions in the protein expressed by the $G 4$ gene in a pair of sequences.

The changes concentrated in the residues from the four proteins are shown in Figure 3 A, B, C, D. In the tax gene phosphorylation sites, B-cell epitope and multifunctional domain were conserved, while we found four changes in the $\mathrm{Zn}$ finger domain, 13 in the T-cell epitopes, and three in the Leucine-rich activation domain. We identified four residue changes in the nuclear export signal (NES) and six changes in the nuclear localization signal (NLS) in the rex gene. In the case of $G 4$, we observed nine changes in myb-like motif (MYB) and four in the arginine-rich nucleus targeting RNA-binding region (ARR). Lastly, in the $R 3$ gene, we identified nine residues with changes in five study sequences.

\section{Discussion}


It was not possible to establish an association between genetic variability in the BLV pX region and the development of lymphocytosis, tumor development, asymptomatic status and proviral load in Holstein Friesian cattle infected with BLV genotype 1.

We obtained 30 sequences measuring $1156 \mathrm{nt}$ in length that corresponded to the BLV pX region. Phylogenetic analysis showed that all of these sequences were associated with BLV genotype 1, which is widely distributed throughout Mexico $[19,20]$. Furthermore, the sequences were grouped heterogeneously throughout the genotype 1 reference sequence clade, not displaying any relationship to infection phase (with and without lymphocytosis or lymphoma) nor geographic origin of the samples.

The R3 protein is made up of 44 amino acids with a hydrophilic portion at the N-terminus followed by a hydrophobic region. [26] described premature stop codons in two sequences obtained from tumor lesions in the $R 3$ gene, but we did not find any premature stop codons in the 30 sequences analysed for this study. While we did find nine non-synonymous mutations in five sequences in the three study groups, we did not identify their possible biological implications (Figure $3 \mathrm{D}$ ).

Although the functions of G4 and R3 proteins have not been fully clarified, they are known to be of great importance for viral propagation in vivo [27]. The oncogenic potential of G4 protein stands out among other known functions. This protein includes an amino terminal stretch of hydrophobic residues, followed by possible proteolytic cleavage sites and a region rich in arginines located in the center of the protein [28]. This region is key in the interaction of G4 with farnesyl pyrophosphate synthetase (FPPS;[29]), an enzyme that participates in the pathway to lipidation of a great variety of nuclear lamin proteins, Ras, other regulatory binding proteins (GTP), as well as various kinases and phosphatases [29] (Lefebvre et al., 2002).

The G4-FPPS interaction has been demonstrated in cell transformation. Mutations in the alpha helix of the arginine-rich region of the $\mathrm{G} 4$ protein, prevent the immortalization of primary cells and the induction of tumors in nude mice [29]. The interruption of the G4-FPPS interaction could alter the process of oncogenesis. In our study sequences, we found four non-synonymous mutations in the arginine-rich region, two of them in abomasum and heart tumor tissues (Figure $3 \mathrm{C}$ ). Although we identified positive selection in the $G 4$ gene in all infected animal groups, the high conservation of the arginine-rich region in the G4 protein may be necessary for it to exert its oncogenic function. We also found many nonsynonymous mutations in the MYB motif, and this many accumulated changes have not been previously described in the literature for this gene. Additionally, we found two sequences with AGU_7488L residue deletions, and three residues (AGU_18A) that coincide with descriptions by Murakami et al. [30]. These authors carried out in vitro analyses and reported a deletion of four amino acids in the G4 gene linked to a decrease in viral production and replication. The high number of changes identified in this region may impact viral replication, but in vitro studies are necessary to demonstrate this.

The Rex protein facilitates viral RNA export from the nucleus to the cytoplasm via nuclear localization (NLS) and nuclear export (NES) signals [31]. NLS directs Rex proteins to the nucleus, except when it binds to viral RNA. This binding masks the NLS, allowing the NES to direct the viral RNA to the cytoplasm 
through nuclear pores [32,33]. In our study sequences we found ten non-synonymous mutations (Figure $3 \mathrm{~B}$ ), four of them were in the NES region in cattle with lymphocytosis, and six in the NLS region. Three of the latter were in cattle without lymphocytosis, two were in cattle with lymphocytosis, and one was in an animal with lymphoma. We only identified mutations in the NES region in cattle with lymphocytosis, where a serine residue exchange for leucine dominated.

The tax gene is involved with transcription of viral and cellular genes, and may allow oncogenic transformation through inhibition of DNA repair pathways in infected cells [34]. The presence of a zinc finger motif, a transactivator motif and two phosphorylation sites have been identified in the Tax protein [26]. A study found that Tax mutants with substitutions in amino acids 240 and 265 had a greater transcriptional capacity directed to LTR than what is seen naturally with the Tax protein [35]. We did not find these substitutions in our study. Den Breoeke et al. [36] reported a mutant with a single substitution (E303K) that turned out to be replication defective, but this substitution was also absent in the sequences we obtained.

Phosphorylation sites, sites associated with transactivation, and B-cell epitopes were conserved in all sequences. Only four mutations were observed in the zinc finger motif, three mutations in the leucine-rich domain in three animals without lymphocytosis, and 13 mutations in T-cell epitopes. None of the substitutions observed in the Tax protein were associated with the previously described regions that impact virus transcription and replication (Figure 3A). While other studies have described mutations in functional domains and important epitopes of this protein, phosphorylation sites are generally conserved [18].

Previous studies have revealed that different genetic and epigenetic mechanisms can silence the tax gene, which is essential for non-progression of tumoral processes [37]. We found high degrees of conservation in our analysis of tax gene sequences, and it was not possible to identify sequence patterns that could be associated with the development of cell transformation, especially in animals with lymphocytosis and tumor tissues.

The genetic distance values obtained from our study $R 3, G 4$, rex and tax gene nucleotide sequences were $0.2-2.09 \%, 0.94-1.18 \%, 0.5-0.8 \%$ and $0.73-0.8 \%$ respectively. Other studies on genotype 1 BLV have identified genetic distances ranging from $0-12.1 \%, 0-6.5 \%, 0-9.4 \%$ and $0-6.1 \%$ for the $R 3, G 4$, rex and tax genes respectively [38]. The maximum genetic distance values described by Panei et al. [38] exceeded the values obtained in our study by up to six times. This may be due to some analyzed sequences being phylogenetically related to genotype 2 (JF288766 and JF288767; Figure 2).

Zhao et al. [34] identified that the tax gene has the highest mean nucleotide variation rate (1.86\%) with respect to the $R 3, G 4$ and rex genes $(1.24,1.29$ and $1.40 \%$, respectively), and in this case tax had the second lowest average variation rate $(0.77 \%)$ compared to rex, G4 and $R 3(0.66,1.1$ and 1.12 , respectively). Genetic distances ranging from $0-2.8 \%$ and $0-4.7 \%$ have been identified for the rex and tax genes respectively. These values are greater than the ones found in our study, and these differences may be explained by the inclusion of genotype 1 and genotype 4 sequences in the analysis [39]. Genetic 
distances in the pX region of genotype 1 genes found in our study showed low variability, regardless of infection phase or geographical origin.

One method for determining genetic variability entails measuring the substitution-rate, primarily in overlapping reading frames, because a synonymous change in one gene may not be neutral in the other. Purifying selection, also known as negative selection, is a type of natural selection in which genetic diversity decreases as a particular trait value (phenotype frequency) stabilizes in the population. In comparison, positive selection increases the frequency of certain variations and occurs when equilibrium in the population has not yet been reached [34]. The proportion of synonymous to non-synonymous substitutions (dN / dS) in our result sequences for the three analyzed cattle groups with respect to the tax, $R 3$ (cattle without lymphocytosis and with tumor development) and rex (cattle with and without lymphocytosis) genes established a negative selection. Similar results for tax and rex genes were described by McGirr and Buehuring [40]. Zhao et al. [34] reported negative selection for the BLV tax gene, which could be due to a higher percentage of its sequence not being superimposed, in comparison to other $\mathrm{pX}$ region genes.

The tax gene has been found to be more conserved than rex in primate lymphotropic T viruses 1 and 2, which are classified in the same genus as BLV. This is consistent with Tax being the most important regulatory protein for Deltavirus behavior. We determined positive selection for experimental sequences obtained for the $R 3$ (cattles with lymphocytosis) and rex (with lymphoma) genes, in addition to all BLV G4 gene sequences obtained from cattle. This would indicate that the virus tries to modify its genome and thus avoid the host's immunity mechanisms, including APOBEC [41].

A first approach to EBL diagnosis can be carried out through clinical signs in cattle with tumors and the subsequent histopathological study of biopsies from these tissues. Tumor tissue histopathological analyses allowed the identification of lymphomas characterized by the proliferation of neoplastic lymphocytes with marked anisocytosis and anisokaryosis, as well as a large number of mitoses. Using the ISH technique, we identified the proviral genome and observed a positive signal in tumor tissues. Similar studies have detected BLV in organ samples from an ISH assay directed at non-coding RNA [42]. Marking in lymphomas was low intensity (Figure $1 \mathrm{C}$ and F), indicating few infected cells. However, these data suggest that the ISH technique may be useful in the study of EBL.

We categorized cattle as having lymphocytosis based on an absolute count of 10,000 lymphocytes $/ \mathrm{mm}^{3}$, and out of 405 BLV seropositive cattle, 54\% ( $n=221)$ had lymphocytosis. These results differ from those described in other studies, including Khudhair et al. [43], who identified $29 \%$ of animals with lymphocytosis. This could be due to low infection rates, as only $7 \%$ of animals in that study were seropositive. It is important to mention that the high numbers of animals with lymphocytosis identified in our study cannot all be associated with BVL infection, as at least three continuous samplings are required to determine persistent lymphocytosis [44] and this was not done in our study. 
The use of real-time PCR allowed us to identify proviral loads across study groups (cattle with and without lymphocytosis, tissues with lymphoma) however we did not find statistically significant differences between them. This may be related to the number of infected cells in animals with lymphocytosis, as observed in tumor cells, which did not allow us to identify differences between the study groups. The lack of difference in proviral load could also be related to the number of samples analyzed in each group [19]. Previous studies have also been unable to correlate proviral load with different infection phases $[45,46]$. On the other hand, Chieh-Wen [47] showed that BLV-induced lymphoma and proviral load are associated with different alleles of BoLA-DRB3 in Holstein cows in Japan, and Kobayashi [48] found that high proviral loads in blood are significant for identifying cattle at high risk for developing lymphomas. While available information on proviral loads suggests that these are an important factor in disease progression, our study did not identify any relation between proviral load, pathogenesis and disease.

Numerous diagnostic methods have been used in BLV infection detection studies (including seroneutralization, radioimmunoassay, IDGA, ELISA, western blot and PCR; [49]), and ELISA and PCR have proven to be highly efficient diagnostic techniques at the herd level $[20,50]$. We identified BLV infection in six regions across Mexico via antibody detection using a commercial ELISA test. We found $55.9 \%$ seropositivity in the study group of 724 Holstein Friesian dairy cattle. Across states, BLV seropositivity ranged between $41 \%$ and $80 \%$, which reveals high infection levels in Mexican dairy herds, as well as a notable increase in BLV infection from previous serological studies [51]. Increasing infection levels coincide with reports from other countries such as the United States with $83.9 \%[45,52]$ and Taiwan with $81.8 \%[53]$.

Most BLV phylogenetic work has focused on the env gene, and particularly on the gp51 region because of its importance as a ligand and antigen, among other functions [54, 55]. A detailed study in 2007 identified seven BLV genotypes through env gene analysis [56]. Genotype 8 was first described in Croatia and later distributed across other geographical regions [57]. Genotypes 9 and 10 were described in Bolivia in 2016 [58], Thailand [59] and Myanmar [12]. Our results show that the pX region may be useful in BLV phylogenetic analyses, however it is necessary to generate sequences that include all the genotypes previously identified via env gene analysis to consolidate this proposal.

In conclusion, we did not find an association between $\mathrm{BLV} \mathrm{pX}$ region $(R 3, G 4$, rex and tax) genetic variability and infected cattle with lymphomas, and with or without lymphocytosis. Although we identified positive selection in three of the four genes that make up the $\mathrm{pX}$ genetic region, we could not find implications of this in BLV pathogenesis. Proviral load quantification did not show significant differences between the three study groups. We identified high BLV seropositivity in the study regions, and an overall a high frequency of BLV genotype 1 infecting dairy cattle in Mexico.

\section{Declarations}

\section{Conflicts of interest}


The authors have no financial or personal interests that could influence or bias the content of this article. The authors declare that they have no competing interests. All authors have seen and approved the manuscript.

\section{Funding information}

This study was funded by FONSEC SAGARPA-CONACyT project 2017-6-292826 and by PIAPI2041. FESC. UNAM “Estudio de la respuesta inmune y genética retroviral”.

\section{Acknowledgments}

We thank the ranchers who kindly provided samples, as well as the staff of the virology, genetics, and molecular biology laboratory of FES Cuautitlán. UNAM. Neli Montero was a student in the MSc program: Programa en Ciencias de la Producción y de la Salud Animal, UNAM and supported by a CONACyT grant scholarship.

\section{References}

1. Bai L, Takeshima S, Isogai E, et al (2015) Novel CD8+ cytotoxic T cell epitopes in bovine leukemia virus with cattle. Vaccine 33:7194-7202. https://doi.org/10.1016/j.vaccine.2015.10.128

2. Felmer R, Zúñiga J, Recabal M, Chávez R (2006) Diagnóstico y tipificación del virus de la leucosis bovina mediante una prueba de PCR-RFLP a partir de ADN extraído desde células somáticas de la leche. Archivos de medicina veterinaria 38:. https://doi.org/10.4067/S0301-732X2006000300009

3. Wu MC, Shanks RD, Lewin HA (1989) Milk and fat production in dairy cattle influenced by advanced subclinical bovine leukemia virus infection. Proceedings of the National Academy of Sciences 86:993-996. https://doi.org/10.1073/pnas.86.3.993

4. Miller JM, Van der Maaten MJ (1982) Bovine Leukosis - Its Importance to the Dairy Industry in the United States. Journal of Dairy Science 65:2194-2203. https://doi.org/10.3168/jds.S00220302(82)82482-X

5. Selim A, Marawan MA, Ali A-F, et al (2020) Seroprevalence of bovine leukemia virus in cattle, buffalo, and camel in Egypt. Tropical Animal Health and Production 52:1207-1210. https://doi.org/10.1007/s11250-019-02105-8

6. Gillet N, Florins A, Boxus M, et al (2007) Mechanisms of leukemogenesis induced by bovine leukemia virus: prospects for novel anti-retroviral therapies in human. Retrovirology 4:18. https://doi.org/10.1186/1742-4690-4-18

7. Hajj H El, Nasr R, Kfoury Y, et al (2012) Animal models on HTLV-1 and related viruses: what did we learn? Frontiers in Microbiology 3:. https://doi.org/10.3389/fmicb.2012.00333

8. Maezawa M, Inokuma H (2020) Analysis of bovine leukemia virus integration sites in cattle under 3 years old with enzootic bovine leukosis. Archives of Virology 165:179-183. https://doi.org/10.1007/s00705-019-04431-6 
9. Aida Y, Murakami H, Takahashi M, Takeshima S-N (2013) Mechanisms of pathogenesis induced by bovine leukemia virus as a model for human T-cell leukemia virus. Frontiers in microbiology 4:328. https://doi.org/10.3389/fmicb.2013.00328

10. Krupovic M, Blomberg J, Coffin JM, et al (2018) Ortervirales: New Virus Order Unifying Five Families of Reverse-Transcribing Viruses. Journal of Virology 92:. https://doi.org/10.1128/JVI.00515-18

11. Pierard V, Guiguen A, Colin L, et al (2010) DNA cytosine methylation in the bovine leukemia virus promoter is associated with latency in a lymphoma-derived B-cell line: Potential involvement of direct inhibition of camp-responsive element (CRE)-binding protein/cre modulator/activation transcription. Journal of Biological Chemistry 285:19434-19449. https://doi.org/10.1074/jbc.M110.107607

12. Polat M, Takeshima S, Aida Y (2017) Epidemiology and genetic diversity of bovine leukemia virus. Virology Journal 14:209. https://doi.org/10.1186/s12985-017-0876-4

13. Sagata N, Yasunaga T, Ohishi K, et al (1984) Comparison of the entire genomes of bovine leukemia virus and human T-cell leukemia virus and characterization of their unidentified open reading frames. The EMBO journal 3:3231-7. https://doi.org/10.1126/science.557842

14. Felber BK, Derse D, Athanassopoulos A, Campbell M PG (1989) Cross-activation of the Rex proteins of HTLV-I and BLV and of the Rev protein of HIV-1 and nonreciprocal interactions with their RNA responsive elements. New Biol 1:318-28

15. Pozzatti R, Vogel J, Jay G (1990) The human T-lymphotropic virus type I tax gene can cooperate with the ras oncogene to induce neoplastic transformation of cells. Molecular and Cellular Biology 10:413-417. https://doi.org/10.1128/MCB.10.1.413

16. Willems $L$, Heremans $H$, Chen $G$, et al (1990) Cooperation between bovine leukaemia virus transactivator protein and Ha-ras oncogene product in cellular transformation. The EMBO journal 9:1577-81

17. Florins A, Gillet N, Boxus M, et al (2007) Even Attenuated Bovine Leukemia Virus Proviruses Can Be Pathogenic in Sheep. Journal of Virology 81:10195-10200. https://doi.org/10.1128/JVI.01058-07

18. Pluta A, Willems L, Douville RN, Kuźmak J (2020) Effects of Naturally Occurring Mutations in Bovine Leukemia Virus 5'-LTR and Tax Gene on Viral Transcriptional Activity. Pathogens 9:836. https://doi.org/10.3390/pathogens9100836

19. Cerón Téllez F, González Méndez AS, Tórtora Pérez JL, et al (2020) Lack of association between amino acid sequences of the bovine leukemia virus envelope and varying stages of infection in dairy cattle. Virus Research 278.. https://doi.org/10.1016/j.virusres.2020.197866

20. Heinecke N, Tórtora J, Martínez HA, et al (2017) Detection and genotyping of bovine leukemia virus in Mexican cattle. Archives of Virology. https://doi.org/10.1007/s00705-017-3477-z

21. Mendiola WPS, Tórtora JL, Martínez HA, et al (2019) Genotyping Based on the LTR Region of Small Ruminant Lentiviruses from Naturally Infected Sheep and Goats from Mexico. BioMed Research International 2019:. https://doi.org/10.1155/2019/4279573

22. Huelsenbeck JP, Ronquist F (2001) MRBAYES: Bayesian inference of phylogenetic trees. Bioinformatics 17:754-755. https://doi.org/10.1093/bioinformatics/17.8.754 
23. Kryazhimskiy S, Plotkin JB (2008) The population genetics of dN/dS. PLoS Genetics 4:. https://doi.org/10.1371/journal.pgen.1000304

24. Livak KJ, Schmittgen TD (2001) Analysis of Relative Gene Expression Data Using Real-Time Quantitative PCR and the 2- $\triangle \triangle$ CT Method. Methods 25:402-408. https://doi.org/10.1006/meth.2001.1262

25. Tolle A, Jahnke H-D, Hasse G (2010) Zur Diagnostik der Rinderleukose und ihrer Bekämpfung in Südniedersachsen. Zentralblatt für Veterinärmedizin Reihe B 12:435-443. https://doi.org/10.1111/j.1439-0450.1965.tb01408.x

26. Moratorio G, Fischer S, Bianchi S, et al (2013) A detailed molecular analysis of complete Bovine Leukemia Virus genomes isolated from B-cell lymphosarcomas. Veterinary Research 44:19. https://doi.org/10.1186/1297-9716-44-19

27. Lefèbvre L, Ciminale V, Vanderplasschen A, et al (2002) Subcellular Localization of the Bovine Proteins Subcellular Localization of the Bovine Leukemia Virus R3 and G4 Accessory Proteins. Journal of virology 76:7843-7854. https://doi.org/10.1128/JVI.76.15.7843

28. Alexandersen S, Carpenter S, Christensen J, et al (1993) Identification of alternatively spliced mRNAs encoding potential new regulatory proteins in cattle infected with bovine leukemia virus. Journal of Virology 67:39-52. https://doi.org/10.1128/JVI.67.1.39-52.1993

29. Lefèbvre L, Vanderplasschen A, Ciminale V, et al (2002) Oncoviral Bovine Leukemia Virus G4 and Human T-Cell Leukemia Virus Type 1 p13II Accessory Proteins Interact with Farnesyl Pyrophosphate Synthetase. Journal of Virology 76:1400-1414. https://doi.org/10.1128/JVI.76.3.1400-1414.2002

30. Murakami H, Uchiyama J, Nikaido S, et al (2016) Inefficient viral replication of bovine leukemia virus induced by spontaneous deletion mutation in the G4 gene. Journal of General Virology 97:27532762. https://doi.org/10.1099/jgv.0.000583

31. Choi E-A, Hope TJ (2005) Mutational Analysis of Bovine Leukemia Virus Rex: Identification of a Dominant-Negative Inhibitor. Journal of Virology 79:7172-7181.

https://doi.org/10.1128/JVI.79.11.7172-7181.2005

32. Kim FJ, Beeche AA, Hunter JJ, et al (1996) Characterization of the nuclear export signal of human Tcell lymphotropic virus type 1 Rex reveals that nuclear export is mediated by position-variable hydrophobic interactions. Molecular and Cellular Biology 16:5147-5155. https://doi.org/10.1128/MCB.16.9.5147

33. Zapp ML, Hope TJ, Parslow TG, Green MR (1991) Oligomerization and RNA binding domains of the type 1 human immunodeficiency virus Rev protein: a dual function for an arginine-rich binding motif. Proceedings of the National Academy of Sciences 88:7734-7738. https://doi.org/10.1073/pnas.88.17.7734

34. Zhao X, McGirr KM, Buehring GC (2007) Potential evolutionary influences on overlapping reading frames in the bovine leukemia virus pXBL region. Genomics 89:502-511. https://doi.org/10.1016/j.ygeno.2006.12.007 
35. Tajima S, Aida Y (2000) The Region between Amino Acids 245 and 265 of the Bovine Leukemia Virus (BLV) Tax Protein Restricts Transactivation Not Only via the BLV Enhancer but Also via Other Retrovirus Enhancers. Journal of Virology 74:10939-10949. https://doi.org/10.1128/JVI.74.23.10939-10949.2000

36. Van Den Broeke A, Bagnis C, Ciesiolka M, et al (1999) In Vivo Rescue of a Silent tax-Deficient Bovine Leukemia Virus from a Tumor-Derived Ovine B-Cell Line by Recombination with a Retrovirally Transduced Wild-Type taxGene. Journal of Virology 73:1054-1065. https://doi.org/10.1128/JVI.73.2.1054-1065.1999

37. Merimi M, Klener P, Szynal M, et al (2007) Complete suppression of viral gene expression is associated with the onset and progression of lymphoid malignancy: observations in Bovine Leukemia Virus-infected sheep. Retrovirology 4:51. https://doi.org/10.1186/1742-4690-4-51

38. Panei CJ, Serena MS, Metz GE, et al (2013) Analysis of the pX region of bovine leukemia virus in different clinical stages of Enzootic Bovine Leukemia in Argentine Holstein cattle. Virus Research 171:97-102. https://doi.org/10.1016/j.virusres.2012.08.001

39. Kazemimanesh M, Madadgar O, Steinbach F, et al (2019) Detection and molecular characterization of bovine leukemia virus in various regions of Iran. Journal of General Virology 100:1315-1327. https://doi.org/10.1099/jgv.0.001303

40. McGirr KM, Buehuring GC (2006) Tax \&amp; Rex: Overlapping Genes of the Deltaretrovirus Group. Virus Genes 32:229-239. https://doi.org/10.1007/s11262-005-6907-z

41. Nakano Y, Aso H, Soper A, et al (2017) A conflict of interest: the evolutionary arms race between mammalian APOBEC3 and lentiviral Vif. Retrovirology 14:31. https://doi.org/10.1186/s12977-0170355-4

42. Andoh K, Kimura K, Nishimori A, Hatama S (2020) Development of an in situ hybridization assay using an AS1 probe for detection of bovine leukemia virus in BLV-induced lymphoma tissues. Archives of Virology 165:2869-2876. https://doi.org/10.1007/s00705-020-04837-7

43. Khudhair YI, Hasso SA, Yaseen NY, Al-Shammari AM (2016) Serological and molecular detection of bovine leukemia virus in cattle in Iraq. Emerging Microbes and Infections 5:e56. https://doi.org/10.1038/emi.2016.60

44. Rajão DS, Heinemann MB, Reis JKP, et al (2014) Effects of bovine leukemia virus infection on crossbred and purebred dairy cattle productive performance in Brazil. Semina: Ciências Agrárias 35:891. https://doi.org/10.5433/1679-0359.2014v35n2p891

45. Bartlett PC, Sordillo LM, Byrem TM, et al (2014) Options for the control of bovine leukemia virus in dairy cattle. Journal of the American Veterinary Medical Association 244:914-922. https://doi.org/10.2460/javma.244.8.914

46. Juliarena MA, Gutierrez SE, Ceriani C (2007) Determination of proviral load in bovine leukemia virusinfected cattle with and without lymphocytosis. American Journal of Veterinary Research 68:12201225. https://doi.org/10.2460/ajvr.68.11.1220 
47. Lo C-W, Borjigin L, Saito S, et al (2020) BoLA-DRB3 Polymorphism is Associated with Differential Susceptibility to Bovine Leukemia Virus-Induced Lymphoma and Proviral Load. Viruses 12:352. https://doi.org/10.3390/v12030352

48. Kobayashi T, Inagaki Y, Ohnuki N, et al (2020) Increasing Bovine leukemia virus (BLV) proviral load is a risk factor for progression of Enzootic bovine leucosis: A prospective study in Japan. Preventive Veterinary Medicine 178:104680. https://doi.org/10.1016/j.prevetmed.2019.04.009

49. Martin D, Arjona A, Soto I, et al (2001) Comparative Study of PCR as a Direct Assay and ELISA and AGID as Indirect Assays for the Detection of Bovine Leukaemia Virus. Journal of Veterinary Medicine Series B 48:97-106. https://doi.org/10.1046/j.1439-0450.2001.00424.x

50. Kalvatchev Z, Walder R, Garzaro D, Barrios M (2000) Detection of Genetic Diversity Among Bovine Immunodeficiency Virus Population by Single-Strand Conformation Polymorphism Analysis. Viral Immunology 13:373-381. https://doi.org/10.1089/08828240050144680

51. Monroy Basilio JL, Tavera FJT, De Aluja AS, et al (1992) Estudio comparativo entre las pruebas de ELISA e inmunodifusión en el diagnóstico de la Leucosis Enzoótica Bovina. 1993 21-25

52. USDA (2008) Bovine Leukosis Virus (BLV) on U.S. Dairy Operations. 1-2

53. Hsieh J-C, Li C-Y, Hsu W-L, Chuang S-T (2019) Molecular Epidemiological and Serological Studies of Bovine Leukemia Virus in Taiwan Dairy Cattle. Frontiers in Veterinary Science 6:. https://doi.org/10.3389/fvets.2019.00427

54. Callebaut I, Vonèche V, Mager A, et al (1993) Mapping of B-neutralizing and T-helper cell epitopes on the bovine leukemia virus external glycoprotein gp51. Journal of Virology 67:5321-5327. https://doi.org/10.1128/JVI.67.9.5321-5327.1993

55. Mamoun RZ, Morisson M, Rebeyrotte N, et al (1990) Sequence variability of bovine leukemia virus env gene and its relevance to the structure and antigenicity of the glycoproteins. Journal of virology 64:4180-8

56. Rodriguez SM, Golemba MD, Campos RH, et al (2009) Bovine leukemia virus can be classified into seven genotypes: evidence for the existence of two novel clades. Journal of General Virology 90:2788-2797. https://doi.org/10.1099/vir.0.011791-0

57. Balić D, Lojkić l, Periškić M, et al (2012) Identification of a new genotype of bovine leukemia virus. Archives of Virology 157:1281-1290. https://doi.org/10.1007/s00705-012-1300-4

58. Polat M, Takeshima S, Hosomichi K, et al (2016) A new genotype of bovine leukemia virus in South America identified by NGS-based whole genome sequencing and molecular evolutionary genetic analysis. Retrovirology 13:4. https://doi.org/10.1186/s12977-016-0239-z

59. Lee EJ, Kim EJ, Ratthanophart J, et al (2016) Molecular epidemiological and serological studies of bovine leukemia virus (BLV) infection in Thailand cattle. Infection, Genetics and Evolution 41:245254. https://doi.org/10.1016/j.meegid.2016.04.010

60. OIE (2012) Enzootic Bovine Leukosis. In: OIE Terrestrial Manual. pp 721-732

\section{Tables}


Table 1. Primers used for amplification of the BLV pX region.

\begin{tabular}{|lll|}
\hline Designation & Sequence $\left(5^{\prime}{ }^{\prime} \mathbf{3}^{\prime}\right)$ & Primer position* \\
\hline Fw1 & TCAGTGTACCATCACAAGCC & $6426-6445$ \\
\hline Rv1 & ACCAACAACACTTGCTTAAA & $7241-7260$ \\
\hline Fw2 & AACAGTGCCCATAAAGTCC & $7100-7118$ \\
\hline Rv2 & CGGTTAGGAATAGGTCGAT & $7978-7996$ \\
\hline Fw3 & ATGGCCAATTTTTCCTTACT & $7708-7727$ \\
\hline Rv3 & ACGTCTCTGTCTGGTTTACG & $8225-8244$ \\
\hline
\end{tabular}

*Primer position was based on the OIE reference sequence with accession number K02120 [60]

Table 2. Serology and absolute lymphocyte count for all analyzed samples, with cattle classed according to provenance from different states.

\begin{tabular}{|llll|}
\hline STATE & ELISA seropositive & $\begin{array}{l}\text { With } \\
\text { lymphocytosis }\end{array}$ & $\begin{array}{l}\text { Without } \\
\text { lymphocytosis }\end{array}$ \\
\hline Aguascalientes & 96 & 50 & 46 \\
\hline Coahuila & 92 & 47 & 45 \\
\hline Guanajuato & 57 & 33 & 24 \\
\hline Hidalgo & 34 & 16 & 18 \\
\hline Puebla & 41 & 35 & 6 \\
\hline Tlaxcala & 85 & 40 & 45 \\
\hline Total & 405 & $221(54 \%)$ & $184(46 \%)$ \\
\hline
\end{tabular}

Table 3. Genetic distance and ratio analyses of BLV synonymous (dS), nonsynonymous (dN) and nucleotide sequences of the Tax, Rex, G4 and R3 genes in infected Friesian Holstein cattle. 


\begin{tabular}{|lllll|}
\hline \multicolumn{3}{|c}{ Substitutions } & & Genetic distance \\
\hline Gene and group & Average dN & Average dS & Average dN/dS & Percentage (\%) \\
\hline tax With lymphocytosis & 0.0050 & 0.0218 & 0.229 & 0.8 \\
\hline tax Without lymphocytosis & 0.0075 & 0.0211 & 0.355 & 0.8 \\
\hline tax & 0.0067 & 0.0190 & 0.352 & 0.73 \\
\hline lymphoma & & & & \\
\hline rex With lymphocytosis & 0.0116 & 0.0241 & 0.481 & 0.5 \\
\hline rex Without lymphocytosis & 0.0136 & 0.0169 & 0.804 & 0.8 \\
\hline rex lymphoma & 0.0253 & 0.0045 & 5.6 & 0.69 \\
\hline & & & & 0.94 \\
\hline G4 With lymphocytosis & 0.0153 & 0.0152 & 1 & 1.18 \\
\hline G4 Without lymphocytosis & 0.0197 & 0.0175 & 1.1 & 1.18 \\
\hline G4 lymphoma & 0.0308 & 0.0228 & 1.3 & 2.09 \\
\hline R3 With lymphocytosis & 0.0632 & 0.0609 & 1.03 & 0.2 \\
\hline$R 3$ Without lymphocytosis & 0.0150 & 0 & 0 & 1.07 \\
\hline$R 3$ lymphoma & 0.0149 & 0.0639 & 0.23 & \\
\hline
\end{tabular}

\section{Figures}




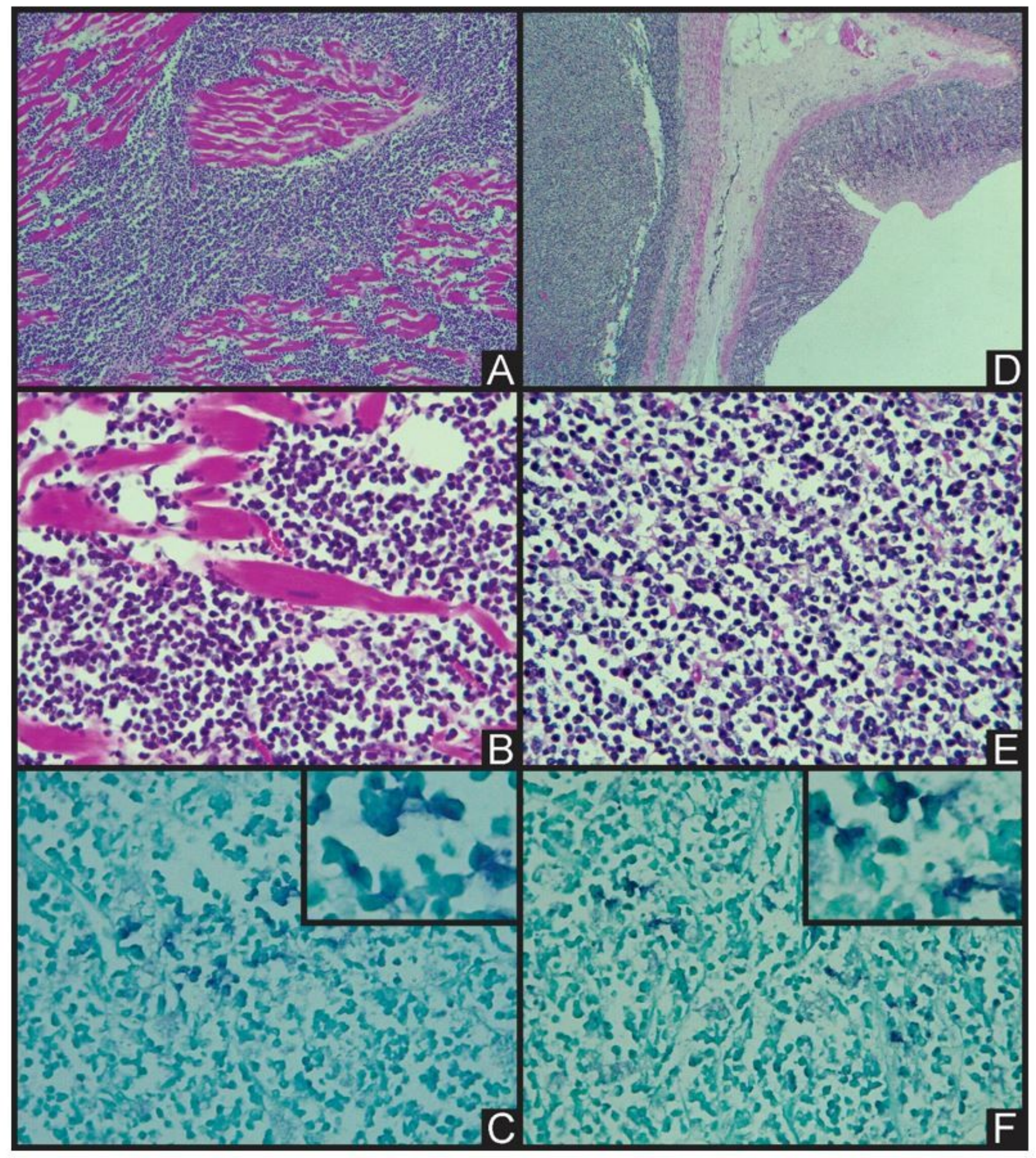

Figure 1

$\mathrm{H}-\mathrm{E}$ staining, histopathological changes. Abundant neoplastic lymphocyte aggregates are visible with marked anisocytosis, located between myocardial fibers and in the mucosa and muscle of the abomasum 40x (A, D) and 400x (B and E). In situ hybridization with fine signals shown in blue, in neoplastic cells located in the heart and abomasum of an animal with lymphomas, with 400x fast green staining. In the upper right frame, images $\mathrm{C}$ and $\mathrm{F}$ show an enlargement of the positive signals. 


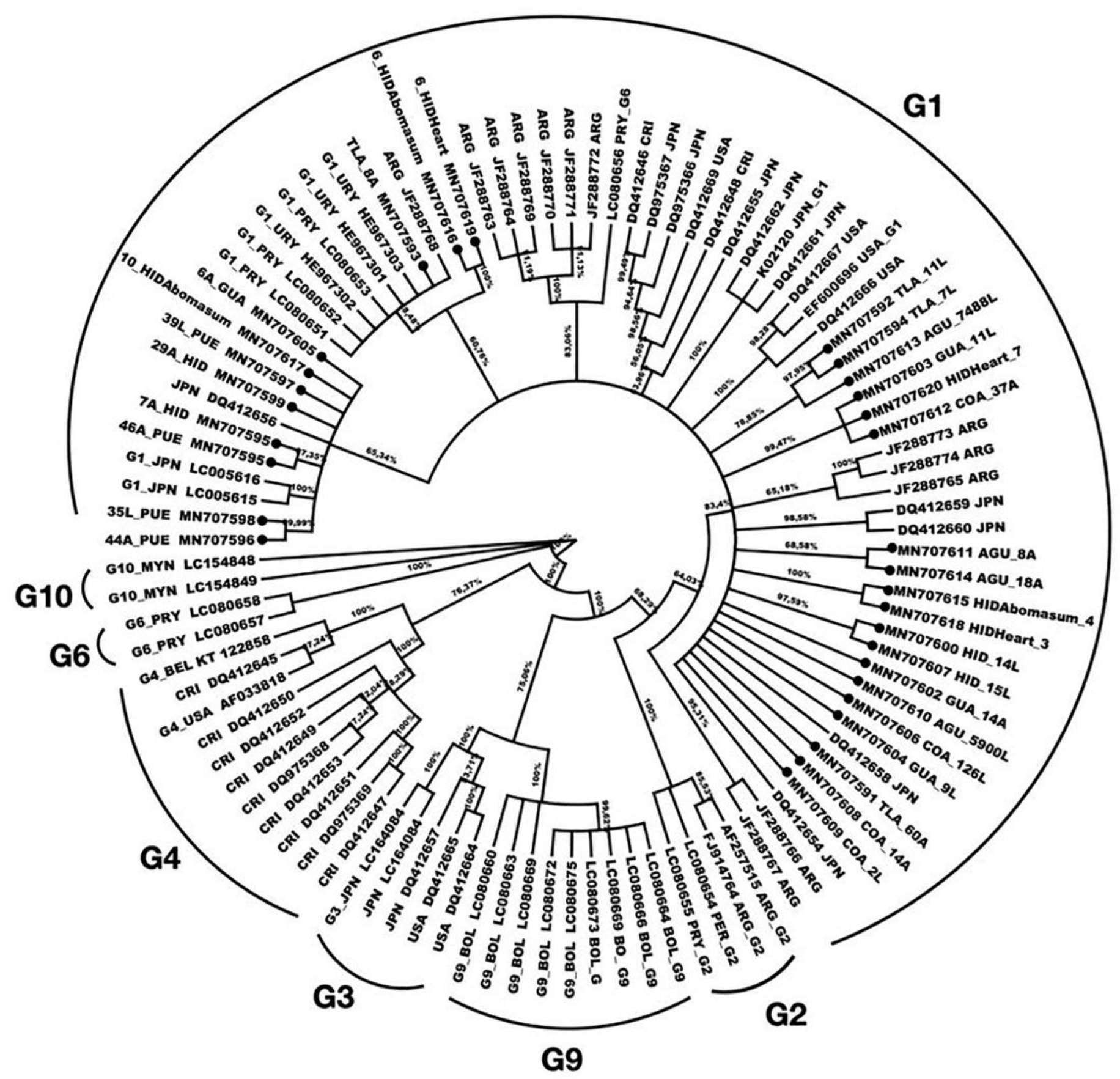

Figure 2

Phylogenetic tree constructed using the Bayesian method and 1000 bootstraps. G1, G2, G3, G4, G6, G9 and $\mathrm{G} 10$ show reference sequences grouping by genotype and () sequences obtained in this study. Identification of sequences in the phylogenetic tree, from the center out: accession number, state abbreviation code (AGU: Aguascalientes, COA: Coahuila, GUA: Guanajuato, HID: Hidalgo, PUE: Puebla and 
TLA: Tlaxcala), and animal identification. L: with lymphocytosis, A: without lymphocytosis. Samples of tumor tissue of the abomasum and heart.
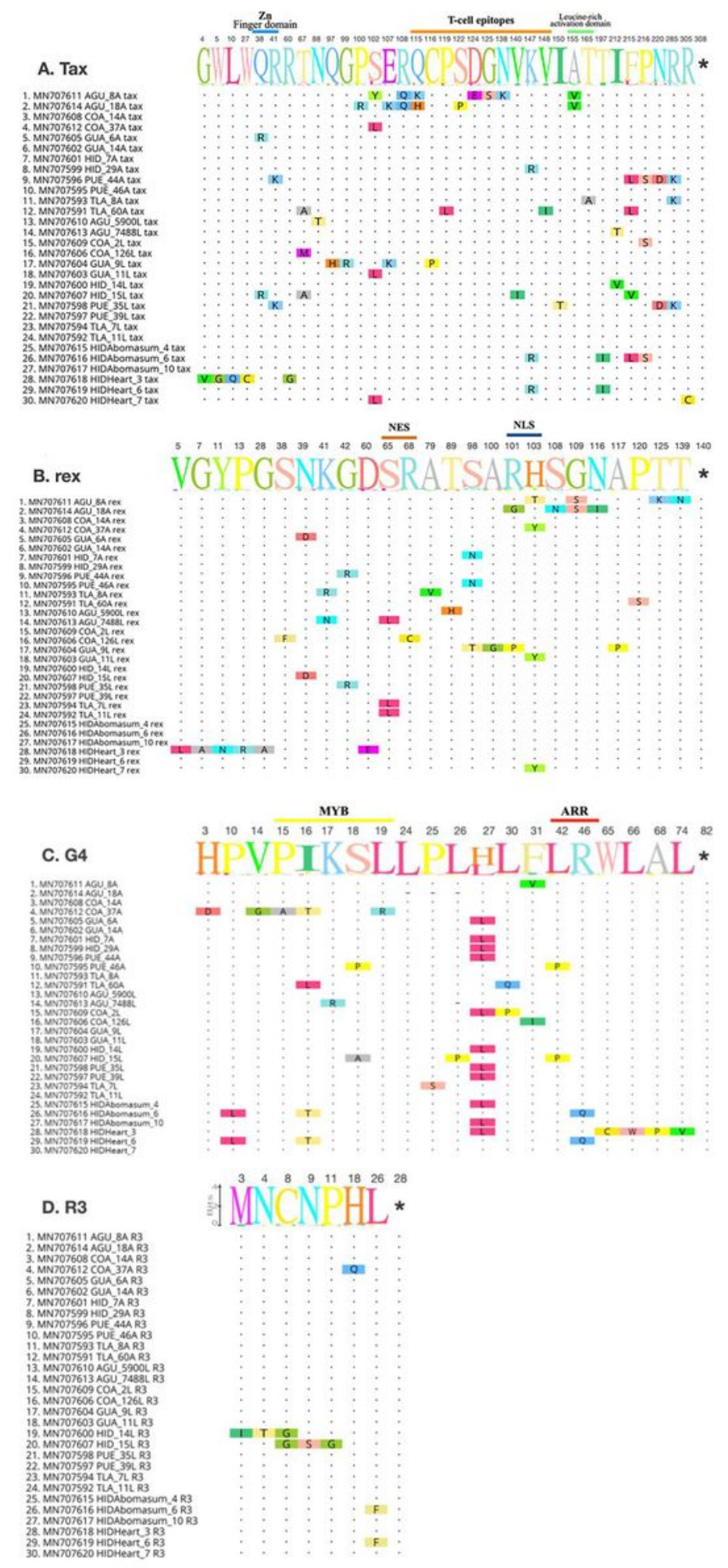

\section{Figure 3}

A, B, C, D: Alignments that show Tax, Rex, G4 and R3 protein amino acid sequences with position changes. The position and residue where at least one residue change was identified in the sequences 
analysed is shown. Numbers indicate the residue number. In the upper part of the image we show a consensus weblog of the amino acids, graphically representing found changes. 